\title{
Investigating the expectations of business management students as future leaders regarding the influence of leadership on organisational strategy: A survey at a South African tertiary institution
}

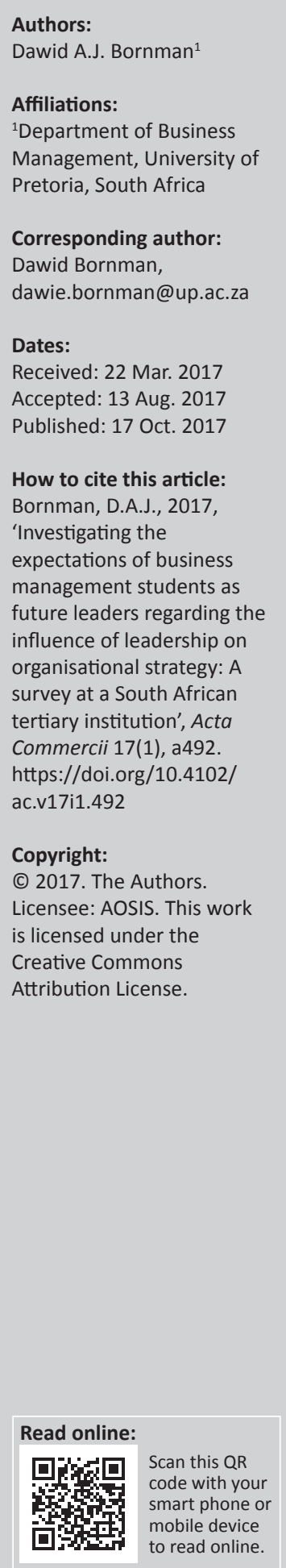

Orientation: Unpredictable technology changes challenge how organisations operate in the global competitive business environment. Organisational strategy needs to be flexible, a capability that is impossible to achieve without effective leadership.

Research purpose: To investigate the expectations of first year undergraduate business management students at a South African tertiary institution towards leadership and to what extent leadership influences organisational strategy.

Motivation for the study: The results of this study contribute towards: (1) providing insight as to how possible future business leaders are expected to behave in order to have an impact on organisational strategy, (2) providing a better understanding of upcoming leadership trends from future generations and (3) business leadership and organisational strategy's interdependence.

Research design, approach and method: Empirical research through a quantitative survey, distributed to 200 first year undergraduate business management students at a South African tertiary institution.

Main findings: (1) That most important leadership style was transformational, (2) emergent strategies were preferred over deliberate strategies and (3) that leadership influence is important to have a successful overall organisational strategy.

Practical and managerial implications: An outline of leadership conduct in terms of the expectations of possible future business leaders and that leadership had an influence on organisational strategy.

Contribution or value added: If effective leadership training and development gets implemented on an early level (i.e. first year undergraduate studies), then future leaders might be able to develop their followers and inspire them to develop as leaders themselves, which could possibly create a longevity of leadership and organisational success.

\section{Introduction}

The world of business has become increasingly unpredictable as technology continues to challenge and change how organisations operate in the global competitive environment. Maritz, Pretorius and Plant (2011:102) state that never before has organisational strategy needed to be so flexible and therefore leadership forms an important part of both the implementation and the formulation of strategy. As the next generation of business leaders are considered to be within the business faculties of tertiary education institutions, their perspective of how business leaders influence organisational strategy is important for its future direction (Čater, Lang \& Szabo 2013:444).

Although literature has seen an increased emphasis on 'strategy-as-practice' as well as the narrative approach to strategy (Carter, Clegg \& Kornberger 2008; Fenton \& Langley 2011; Kahane 2017; Schoemaker \& Krupp 2015), Maritz et al. (2011:103) point out that business leaders are being seen as the architects of strategy and play a fundamental role in the successful pursuit of both deliberate and emerging strategies.

Therefore, this study focuses on the expectations of possible future business leaders (i.e. first year undergraduate business management students) on whether within their future working 
environments or organisations: (1) if the transformational leadership style would be preferred over the transactional leadership style, (2) whether emerging strategy would be preferred over deliberate strategy as well as (3) if leadership would have an influence on the success of organisational strategy.

To understand the influence of leadership on organisations, Sarros et al. (2014:228-229) utilised the Motivating Language Theory model. Mayfield, Mayfield and Sharbrough (2015:97) reconceptualised this theory to create a model that can assess how top organisational leaders can transmit organisational visions (as part of the organisational strategy), as well as how these leaders improve the organisational performance. Mayfield et al. (2015:115) further draw the conclusion that leaders in business or organisational environments have the crucial role of communicating the organisational vision to both the internal and external stakeholders.

\section{Problem statement}

The problem at hand is not whether leadership plays a vital role in the formulation or implementation of an organisational strategy, but what the expectations of possible future business leaders (i.e. first year undergraduate business management students) are in terms of the influence of leadership on organisational strategy.

The phenomenon of the leadership expectations held by students, and its influence on organisational strategy, has largely been untouched in a South African context and no evidence was found of such research in the context of economic and management science students at a South African tertiary institution. Therefore, this study aims to bridge this gap that is evident in the body of knowledge in this specific focus area.

\section{Research objectives}

By taking the problem statement into account, the study's research objectives are:

- to determine if first year undergraduate business management students expect the transformational leadership style to be more important than the transactional leadership style in the practice of organisational strategy

- to determine whether first year undergraduate business management students expect emerging strategy to be more important than deliberate strategy in the current dynamic business environment

- to determine the influence that first year undergraduate business management students expect leadership will have on organisational strategy.

Current business leaders can use this study to better understand upcoming leadership trends from future generations in order to efficiently manage their roles and contributions towards organisational strategy as these current leaders are the individuals who will help develop future leaders (Birasnav 2014:206). The results of this study could also contribute to provide further insights into how future business leaders are expected to behave for them to have a successful influence on their prospective working environment's organisational strategy.

\section{Literature review}

In this section of this study, key terms and concepts are investigated. These include leadership (including transformational and transactional leadership), organisational strategy (strategy in the workplace, strategy-as-practice and strategy as a narrative) and a review of how leadership and strategy function and are synthesised together.

\section{Leadership}

In the traditional sense, leadership is seen as being a hierarchical (i.e. top-down) management approach where decisions and actions are primarily made and discussed by top-level management and carried out through the lower levels (Denning 2015:14). An emergent view of leadership is that it is formed and present throughout the organisation where strategies and actions are collectively created on a linear organisational structure where all voices are heard and are equal. This type of communication and linear structure is seen as strategic communication conveyed between members in an organisation as leadership, not as creating a followership or forming order (Raelin 2011:200).

\section{Yukl (2006) states that leadership is:}

the process of influencing others to understand and agree about what needs to be done and how to do it, and the process of facilitating individual and collective efforts to accomplish shared objectives. (p. 8)

Without leadership in an organisation there is no dictation of which direction an organisation should be heading in as the communication and actions of leaders illustrate the inner thinking of organisations and, at a larger scale, society (Sarros et al. 2014:228). Schoemaker and Krupp (2015) add to this notion by stating that leaders are able to extract raw data and interpret that into meaningful information, that is, they are able to devise strategic options for realising the organisations' vision and create structured plans to follow.

The process of leadership is constantly changing as individuals experience and perceive unique leadership moments recurrently. It is therefore important to note that leadership is implemented in various ways grounded on a leader's characteristics or traits, as well as the leadership style chosen by the specific leader (Bornman \& Puth 2017:7). For the purpose of this study, the two foremost leadership styles will be investigated: transactional and transformational leadership styles.

\section{Transactional leadership versus transformational leadership}

Bass and Riggio (in Birasnav 2014:207) define transactional leadership as a process where employees are rewarded or 
punished according to their performance in achieving predetermined goals. Transactional leadership has deep focus on individual interests and outcomes, and its success is based on the transfers of information and order between a leader and their followers (İşcan, Ersarı \& Naktiyok 2014:882; Kunnanatt 2016).

In comparison to the transactional leadership style, the transformational leadership style showcases how leaders take on a more inclusive decision style and tend to be more charismatic while looking at influencing co-workers or challenging the norm by seeking new possibilities (Allio 2016; Tatum \& Eberlin 2007:304). Bass and Riggio (in Birasnav 2014:207) define transformational leadership as behaviour that inspires and motivates employees to commit to achieve a shared vision and transform employees into creators or innovators. For transformational leadership to be realised, strong transactional leadership can assist to serve as a foundation to build from (Breevaart et al. 2014:1).

Within the transformational leadership style, leaders are greatly involved in all aspects of the organisation and tackle conflict head on to get to the best solution. Leaders are concerned with decentralising power and thus give employees freedom of decision-making (Giessner \& Wong 2017:3). The transformational leadership approach gives an organisational employee a chance to be their own leader, providing them with freedom to take on problems and create solutions for themselves. Furthermore, Giessner and Wong (2017:3) point out that self-guidance is created by letting employees think for themselves, which breaks the norm of having to carry down orders from top-level management. This in turn creates a more creative and emergent organisation.

\section{Organisational strategy Strategy in the work place}

Organisational strategy is the way in which a company or an organisation would go about achieving its various objectives set out by top management, within their industry (Carpenter \& Sanders 2014:11). There are two main types of organisational strategy: deliberate strategy and emergent strategy (Kopmann, Kock, Killen \& Gemünden 2017:555). A deliberate strategy is a more formal and planned process where leaders play the role of strategic architects, whereas an emergent strategy comes from an adaptive process that was unplanned (Kahane 2017; Maritz et al. 2011:110; Pretorius \& Maritz 2011:25).

Kopmann et al. (2017:555) state that the emergent strategy has become a major focus of more recent organisational strategy literature because of how markets have evolved to become dynamic and complex environments. Successful strategy implementation would often go amiss without the capability to adapt as the business environment does. This is not to say that the deliberate strategy should not exist though. Maritz et al. (2011:110) suggest that deliberate and emergent strategy making are done in conjunction with one another. A deliberate strategy should be formulated when an intended specific strategy needs to be implemented. In the case of the need for flexibility and change, an emergent strategy should be formulated and implemented, changing the originally intended strategy.

While planned and specific systematic action represents that of the 'intended' or deliberate strategy, the incremental actions that inevitably follow change that deliberate strategy into what is known as the realised strategy. In other words, the formulated deliberate strategy is what the organisation intends to implement, but the emergent strategies that arise from change in the business environment transform this intended strategy into a realised strategy (Brews \& Hunt 1999:903). It is clear that the emergent strategy plays a vital role in the flexibility and adaptability needed in current dynamic markets, something that would be impossible through the sole use of a deliberate strategy.

\section{Strategy-as-practice and strategy as a narrative}

Carter et al. (2008:86) suggest that strategy-as-practice describes strategy as an activity, rather than a possession, assumed by the people of the organisation to carry out. Strategy-as-practice's primary concern is that of performing the actual strategy. For this concept to be applied successfully, Whittington (2006:619) identified three critical P's of strategyas-practice. These are practitioners (i.e. the people who perform strategic activities and carry out its various practices), practices (i.e. the procedures, norms and traditions that form part of the organisation's shared routines of behaviour) and praxis (i.e. the actual activities, both formal and informal, performed by the practitioners in which strategy is done).

A recent trend in literature which gives rise to strategy as a narrative is implemented through the activity of storytelling which assists organisational employees to realise the strategy being pursued (Kopmann et al. 2017:555; Küpers, Mantere \& Statler 2013:84). Mayfield et al. (2015:100) describe the storytelling aspect of strategy as what generates sensemaking in terms of the strategy. This sense-making occurs through both the formal and informal practices within the organisation, via leaders. Within the organisational context, leaders tell stories in order to aid co-workers in their interpretation of what the strategy is and how it is to be pursued.

\section{Leadership and organisational strategy interdependence}

The role of leadership in organisational strategy is vital to its existence as the influence of business leaders can be felt in the formulation, implementation and communication of the organisational strategy (Giessner \& Wong 2017:3; Maritz et al. 2011:102-103). The organisational strategy, whether deliberate or emergent, therefore cannot exist without leadership.

Marx (2015:111) states that leadership affects the formulation of strategy and that strategy affects leaders throughout the organisation responsible for implementing the strategy. The success of the strategy implementation is dependent on how 
well leaders adapt to the strategy. If the leadership fails to make the adaptations necessary to implement the strategy effectively, then the strategy will not be successful.

A leader within an organisational context is therefore seen as acting as a strategic architect, and in achieving a successful organisational strategy, the leader's strategic vision capabilities and the ability to convey its strategic vision prove to be vital (Mayfield et al. 2015:98).

\section{Hypotheses}

Transactional leadership can be seen as a very effective and important leadership style as it guarantees that the objectives of leaders are met. On the other hand, transformational leadership can be seen as even more important as the objectives of the leader are met above and beyond expectations and done by building a strong base of employee motivation (Breevaart et al. 2014:139). Thus, the first hypothesis that was formulated states the following:

$\mathrm{H}_{1}$ : First year business management students regard a transformational leadership style as more important than a transactional leadership style in the practice of organisational strategy.

While a deliberate strategy still remains valuable, the successful implementation of an emergent strategy plays a crucial role in dynamic business environments (Giessner \& Wong 2017:3; Maritz et al. 2011:110; Porter 1996:61). This gave rise to the formulation of a second hypothesis as follows:

$\mathrm{H}_{2}$ : First year business management students regard emerging strategies as more important than deliberate strategies in the current dynamic business environment.

Carmeli and Waldman (2009) argue that leadership plays a vital role in communicating strategy and that without its existence the success of strategy would be inaccessible and the direction of operations would not be comprehended. Taking this into account the following hypothesis was formulated:

$\mathrm{H}_{3}$ : First year business management students view leadership as important in order to have a successful organisational strategy.

\section{Methodology Sampling}

The target population for this quantitative study comprised male and female first year undergraduate business management students on the main campus of a South African tertiary institution. The target sample size was 200 respondents and the context of this study took place in a classroom setting where students voluntarily filled out a survey in the first $10 \mathrm{~min}$ of their business management lecture. The realised sample size achieved was 197 completed surveys with a response rate of $93.81 \%$. Because the purpose of this study was to determine the expectations of these students about leadership's influence on organisational strategy, the units of analysis were the individual first year undergraduate business management students.
The study was conducted by using a non-probability sampling method, more specifically quota sampling, as there was no specific sampling frame. The use of quota sampling ensures that sub-population members are also included in the sample, thus better representing the population (University of Pretoria 2015a:16). In this study, the quota sampling is non-proportional, which means that the size of the quota groups is not essentially proportional to the size of the groups in the target population and that the size of the quota groups was exclusively determined (University of Pretoria 2015b:2).

\section{Data collection}

For the pre-testing, 10 undergraduate students of the Economics and Management Science faculty, who were either taking business management at a first year level or had taken business management at a first year level prior to this study, were chosen. Each of these pretest respondents was asked to firstly sign a form indicating written consent of taking part in the pretest and also to make sure that all ethical procedures were followed. A collaborative respondent pretest was conducted where respondents were actively debriefed in order to determine any problems in the questionnaire in real time (Cooper \& Schindler 2014).

As the target population was business management students, it was assumed that they had a general knowledge regarding the study's key concepts and that the survey could be a self-administered survey through a central location intercept. As this study was conducted at a South African tertiary institution, ethical clearance had to be obtained from the Economics and Management Science faculty research committee. After the study and the research to be conducted were approved, the researcher was allowed to distribute the questionnaire. All respondents had to sign a form of consent for taking part in the study and no incentives were provided to the respondents in order for them to complete the survey.

\section{Measures and data analysis Leadership (in a business context)}

The measurement instrument that was utilised was adapted from Restivo (n.d.), where a five-point Likert-type scale was used. The items in the original survey measured how leaders should be in general, but were adapted for this study to measure leadership in a business context. The measurement scales were labelled from 1 ('unimportant') to 5 ('extremely important') and a higher score on this scale indicated a higher level of agreement with each statement made in each item. The two sub-dimensions in this construct included the student's expectations of (1) transactional leadership and (2) transformational leadership. In total eight questionnaire items focused on these two subdimensions. No items were reverse-scored and the composite scale scores were averaged to calculate the scale scores for each of the items (Restivo, n.d.). 


\section{Organisational strategy}

The measurement of responses for this construct was performed through the use of a five-point Likert-type scale, ranging from 1 ('unimportant') to 5 ('extremely important'). The items measuring this construct are items that have been developed from the literature on organisational strategy. None of the items have been reverse-scored and the three subdimensions of this construct include the student's expectations on (1) emerging strategies, (2) deliberate strategies and (3) strategy in general. The item scores were averaged to calculate the various scores for the items and nine questionnaire items were used to distinguish between these three sub-dimensions.

\section{Leadership's influence on organisational strategy}

The measurement of responses for this construct was also performed through the use of a five-point Likert-type scale, ranging from 1 ('unimportant') to 5 ('extremely important'). None of the items measuring this construct have been reverse-scored, and five questionnaire items were utilised; thus, a higher score on an item indicates a higher level of agreement for that item.

\section{Reliability and validity}

To ensure the reliability of the study, aspects such as credibility, transferability, dependability, conformability and authenticity were taken into account (Bryman \& Bell 2011:410). After the collection of the data, the data were transferred into an electronic format using software such as Qualtrics, Excel and SPSS. This also assisted to determine if data were missing or incomplete, and therefore some responses were discarded from the data analysis for quality control purposes.

In terms of validity, the data collection method was compared with the study by Restivo (n.d.) - as the study adapted the multifactor leadership questionnaire utilised in Restivo's study - to develop a more conduced survey. The literature assisted to correctly define the various concepts and categories within this study.

\section{Results}

\section{Descriptive statistics}

Table 1 contains the descriptive statistics of the various subdimensions that were utilised in order to determine the results of this study's interval data.

TABLE 1: Descriptive statistics for composite scores used to test hypotheses 1 to $3(n=197)$.

\begin{tabular}{|c|c|c|c|c|c|}
\hline \multirow{2}{*}{$\frac{\text { Sub-dimension }}{\text { Transformational leadership }}$} & \multirow{2}{*}{$\frac{M}{4.04}$} & \multicolumn{2}{|c|}{$S D$} & \multicolumn{2}{|c|}{ Cronbach's alpha } \\
\hline & & 1.1 .1 & 0.64 & 1.1 .2 & 0.537 \\
\hline Transactional leadership & 3.87 & 1.1 .3 & 0.68 & 1.1 .4 & 0.180 \\
\hline Emergent strategy & 3.86 & 1.1 .5 & 0.64 & 1.1 .6 & 0.527 \\
\hline Deliberate strategy & 3.14 & 1.1 .7 & 0.75 & 1.1 .8 & 0.562 \\
\hline General strategy & 4.33 & 1.1 .9 & 0.67 & 1.1 .10 & 0.489 \\
\hline $\begin{array}{l}\text { Leadership's influence on } \\
\text { organisational strategy }\end{array}$ & 3.88 & 1.1 .11 & 0.61 & 1.1 .12 & 0.712 \\
\hline
\end{tabular}

The column labelled 'SD' in Table 1 shows that there was a fairly narrow spread in responses across all six subdimensions. These small standard deviations indicate that the respondents answered the questionnaire in a similar way. Transformational leadership had a score (i.e. a mean score of 4.04 and a standard deviation score of 0.64 ) which was higher than transactional leadership. This mean score indicates that the respondents, on average, chose a scale rating between 4 and 5, representing 'very important' and 'extremely important', respectively. Thus, the respondents found the sub-dimension of transformational leadership to be of higher importance than the sub-dimension of transactional leadership.

Emergent strategy had a mean score of $3.86(S D=0.64)$, while deliberate strategy had a mean score of $3.14(S D=0.75)$, which indicated that the respondents, on average, chose a scale rating between 3 and 4 , representing 'quite important' and 'very important', respectively, for these two subdimensions. Although emergent strategy had a higher mean score than deliberate strategy, general strategy consisted of the highest mean score of $4.33(S D=0.67)$ within the strategy construct. This indicates that the respondents, on average, chose a scale rating between 4 and 5, representing 'very important' and 'extremely important', respectively. Thus, the respondents found the sub-dimension of general strategy to be of higher importance than the other sub-dimensions measuring strategy.

Leadership's influence on organisational strategy had a mean score of $3.88(S D=0.61)$. This mean score indicates that the respondents, on average, chose a scale rating between 3 and 4, representing 'quite important' and 'very important', respectively. Thus, the respondents found the construct of leadership's influence on organisational strategy to be fairly important.

Although these results do not provide conclusive evidence to achieve the research objectives set out for this study, they provide some insight and support towards them, and can be seen as generalised conclusions across the different constructs of this study.

In terms of nominal and ordinal data, the socio-demographic profile of the respondents indicated that the majority of respondents fell into the 18-24 years old age group (97.5\%). Respondents in this age group, and being the majority, are in line with the targeted population of this study, as these students may possibly become future business leaders. For the gender variable, the female respondents had the largest share $(60.9 \%)$ in the sample group, and male respondents made up the other portion of the sample (39.1\%). The gender distribution for this study was dependent on how many male and female students were in the lecture at the time of the data collection.

\section{Hypothesis tests}

The first hypothesis $\left(\mathrm{H}_{1}\right)$ focuses on whether first year management students regard a transformational leadership 
style to be more important in organisational strategies than a transactional leadership style. The null and alternative hypotheses of $\mathrm{H}_{1}$ are stated below:

$\mathrm{H}_{1 \text { (null) }}$ : First year management students do not regard a transformational leadership style as more important than a transactional leadership style in the practice of organisational strategy.

$\mathrm{H}_{1 \text { (alt) }}$ : First year management students regard a transformational leadership style as more important than a transactional leadership style in the practice of organisational strategy.

Taking into consideration the descriptive statistics regarding leadership styles, the mean of a transformational leadership style $(M=4.04, S D=0.64)$ was higher than that of a transactional leadership style $(M=3.87, S D=0.68)$, with a difference of 0.17 (4.04-3.87). This indicates a higher level of importance and therefore these descriptive statistics suggest that first year business management students see transformational leadership to be more important than transactional leadership, confirming $\mathrm{H}_{1(\text { alt) }}$. This one-tailed (directional) hypothesis was tested at a $5 \%$ level of significance (i.e. $\alpha=0.05$ ).

The leadership construct was measured at an interval level of measurement as the hypothesis tested the difference between two variables, and $t$-test for a pair was used (Kotzé 2012:46). Because of the repeated measures and the complexity of an analysis of variance (ANOVA) test, a paired samples $t$-test was instead used to test the hypothesis (Field in Kotzé 2012:46). Subsequently, because the paired samples $t$-test showed normality, it was used to test hypothesis $1\left(\mathrm{H}_{1}\right)$.

The results from the paired samples $t$-test are summarised in Table 2. The relevant $p$-values are displayed in the last column.

Because the $p$-value for the paired samples $t$-test on these sub-dimensions (i.e. transformational and transactional leadership through eight items in the survey) is smaller than $0.05(p=0.002)$, it can be concluded that the difference in respondents' average scores on the transformational leadership $(M=4.04, S D=0.64)$ and transactional leadership $(M=3.87, S D=0.68)$ sub-dimensions of business leadership is statistically significant. In order to further confirm the assumption of normality, a Kolmogorov-Smirnov test of normality regarding the transformational leadership and transactional leadership was conducted (see Table 3).

As the descriptive statistics suggest that first year business management students see transformational leadership to be more important than transactional leadership, and the Kolmogorov-Smirnov test furthermore also showed a perfect normal distribution through a histogram and a normal probability plot, $\mathrm{H}_{1 \text { (alt) }}$ can be confirmed (i.e. the alternative hypothesis).

The second hypothesis $\left(\mathrm{H}_{2}\right)$ focused on whether first year business management students regard emergent strategies to be more important than deliberate strategies in the current dynamic business environment. The null and alternative hypotheses of $\mathrm{H}_{2}$ are stated below:

$\mathrm{H}_{2 \text { (null): }}$ : First year business management students do not regard emerging strategies as more important than deliberate strategies in the current dynamic business environment.

$\mathrm{H}_{2(\text { alt })}:$ First year business management students regard emerging strategies as more important than deliberate strategies in the current dynamic business environment.

This is a one-tailed (directional) hypothesis that was tested at a $5 \%$ level of significance (i.e. $\alpha=0.05$ ).

The mean score of the emergent strategy $(M=3.86, S D=0.64)$ was higher than the mean score of deliberate strategy $(M=3.14, S D=0.75)$ with a difference of 0.72 (3.86-3.14). The higher score on the scale indicates a higher level of importance and therefore these descriptive statistics suggest that emergent strategies are in fact seen as more important than deliberate strategies.

Organisational strategy was measured at an interval level of measurement and this hypothesis tested the difference between two variables; thus, either a $t$-test for the pair or a repeated measure ANOVA should be used (Kotzé 2012:46). Because of the repeated measures and the complexity of an ANOVA test, a paired samples $t$-test was used to test the hypothesis.

A paired samples $t$-test is based on the assumption that the difference between the scores from each respondent has a

TABLE 2: Results of the paired samples $t$-test for differences in mean scores of transformational leadership and transactional leadership.

\begin{tabular}{|c|c|c|c|c|c|c|c|c|}
\hline \multirow[t]{2}{*}{ Variable } & \multicolumn{3}{|c|}{ Paired differences } & \multicolumn{2}{|c|}{$95 \%$ Confidence interval of the difference } & \multirow[t]{2}{*}{$t$} & \multirow[t]{2}{*}{$d f$} & \multirow[t]{2}{*}{$p$} \\
\hline & Mean & Std. deviation & Std. error mean & Lower & Upper & & & \\
\hline $\begin{array}{l}\text { A transformational leadership style is more } \\
\text { important than a transactional leadership style. }\end{array}$ & 0.17 & 0.75 & 0.05 & 0.06 & 0.27 & 3.11 & 196 & 0.002 \\
\hline
\end{tabular}

Source: Author's own work

$d f$, degrees of freedom.

TABLE 3: Statistical analysis of the difference between transformational leadership and transactional leadership using Kolmogorov-Smirnov test for normality.

\begin{tabular}{|c|c|c|c|c|c|c|}
\hline \multirow[t]{2}{*}{ Variable } & \multicolumn{3}{|c|}{ Kolmogorov-Smirnov ${ }^{a}$} & \multicolumn{3}{|c|}{ Shapiro-Wilk } \\
\hline & Statistic & $d f$ & Sig. & Statistic & $d f$ & Sig. \\
\hline $\begin{array}{l}\text { Difference between transformational } \\
\text { leadership and transactional leadership }\end{array}$ & 0.085 & 197 & 0.001 & 0.985 & 197 & 0.033 \\
\hline
\end{tabular}

Source: Author's own work

$d f$, degrees of freedom.

a, Lilliefors significance correlation 
normal distribution. Firstly, difference scores were generated for the pair of variables (i.e. emergent strategy and deliberate strategy), and then the normality was tested for these scores. The results from the paired samples $t$-test are summarised in Table 4 . The relevant $p$-values are displayed in the last column.

To test the normality of these scores, a visual inspection of a histogram and a normal probability plot was done through a Kolmogorov-Smirnov test (Kotzé 2012:49). These tests show that the difference scores for the emergent strategy, deliberate strategy and strategy in general sub-dimensions achieved normality (see Table 5). Subsequently, because the paired samples $t$-test showed normality, it was used to test hypothesis $2\left(\mathrm{H}_{2}\right)$.

As the $p$-value for the paired samples $t$-test on these subdimensions is smaller than $0.05(p<0.001)$, it can be concluded that the difference in respondents' average scores on the emergent strategy $(M=3.86, S D=0.63)$ and deliberate strategy $(M=3.14, S D=0.75)$ sub-dimensions of leadership is statistically significant. The higher score on the scale indicates a higher level of importance and therefore these descriptive statistics suggest that emergent strategies are in fact seen as more important than deliberate strategies. Along with the Kolmogorov-Smirnov test which showed a perfect normal distribution on a histogram and normal probability plot regarding emergent strategy and deliberate strategy, $\mathrm{H}_{\text {2(alt) }}$ can be confirmed (i.e. the alternative hypothesis).

The third hypothesis $\left(\mathrm{H}_{3}\right)$ focuses on the influence of leadership in the success of an organisational strategy. The null and alternative hypotheses of $\mathrm{H}_{3}$ are stated below:

$\mathrm{H}_{3 \text { (null) }}$ : First year business management students do not view leadership as important in order to have a successful organisational strategy.

$\mathrm{H}_{3(\mathrm{alt})}$ : First year business management students view leadership as important in order to have a successful organisational strategy.

The leadership importance of successful organisational strategy construct has a composite mean score of 3.88 $(S D=0.61)$. This is a two-tailed (non-directional) hypothesis and a higher score on the scale indicates a higher level of importance. Therefore, this mean score indicates that the respondents found leadership to have a fairly important influence on organisational strategy, and a KolmogorovSmirnov test furthermore showed a perfect normal distribution through a histogram and a normal probability plot. Thus, $\mathrm{H}_{3(\text { alt) }}$ can be confirmed (i.e. the alternative hypothesis).

\section{Discussion}

This study investigated first year undergraduate business management students' expectations of leadership in terms of the influence transformational and transactional leadership styles have on organisational strategy, the processes of emergent and deliberate strategies and whether leadership has an influence on a successful organisational strategy.

\section{Summary of findings}

Hypothesis 1 stated that a transformational leadership style would be more important than a transactional leadership style in the practice of organisational strategy. This hypothesis was accepted because of the transformational leadership style receiving a score higher than that of the transactional leadership style. These scores that were produced in terms of the two sub-dimensions' means showed that there was only a slightly higher score for transformational leadership style compared to the transactional leadership style. These findings are in line with previous studies as transactional leadership can be seen as the starting point for leaders to eventually adopt a transformational leadership style (Breevaart et al. 2014:1).

This hypothesis that measured the leadership construct has a general tendency towards a transformational leadership style $(M=4.04)$ over a transactional leadership style $(M=3.87)$. The results also imply that the respondents understand the influence that leadership has in an organisation, specifically on the success of an organisational strategy, as well as their own expectations in terms of which leadership style they would prefer when conducting business.

The results achieved for hypothesis 2 showed a marginally significant difference (0.72) in the mean scores between the sub-dimensions for organisational strategy. Both emergent

TABLE 4: Results of the paired samples $t$-test for differences in mean scores of emergent strategy and deliberate strategy.

\begin{tabular}{|c|c|c|c|c|c|c|c|c|}
\hline \multirow[t]{2}{*}{ Variable } & \multicolumn{3}{|c|}{ Paired differences } & \multicolumn{2}{|c|}{$95 \%$ Confidence interval of the difference } & \multirow[t]{2}{*}{$t$} & \multirow[t]{2}{*}{$d f$} & \multirow[t]{2}{*}{$p$} \\
\hline & Mean & Std. deviation & Std. error mean & Lower & Upper & & & \\
\hline $\begin{array}{l}\text { Emerging strategies are more } \\
\text { important than deliberate strategies. }\end{array}$ & 0.72 & 0.98 & 0.07 & 0.59 & 0.86 & 10.34 & 196 & 0.000 \\
\hline
\end{tabular}

Source: Author's own work

$d f$, degrees of freedom.

TABLE 5: Statistical analysis of the difference between emergent strategy and deliberate strategy using Kolmogorov-Smirnov test for normality.

\begin{tabular}{|c|c|c|c|c|c|c|}
\hline \multirow[t]{2}{*}{ Variable } & \multicolumn{3}{|c|}{ Kolmogorov-Smirnov ${ }^{\mathrm{a}}$} & \multicolumn{3}{|c|}{ Shapiro-Wilk } \\
\hline & Statistic & $d f$ & Sig. & Statistic & $d f$ & Sig. \\
\hline $\begin{array}{l}\text { Difference between emergent } \\
\text { strategy and deliberate strategy }\end{array}$ & 0.051 & 197 & $0.200 *$ & 0.995 & 197 & 0.803 \\
\hline
\end{tabular}

Source: Author's own work

$d f$, degrees of freedom.

a, Lilliefors significance correlation; *, the lower bound of the true significance. 
strategy $(M=3.86)$ and deliberate strategy $(M=3.14)$, with similar scores, were expected, with emergent strategy being slightly higher. This hypothesis was accepted on the basis of its descriptive statistics. The results show that an emergent strategy is more important in the current dynamic business environment because of ever-changing factors. However, it can be noted that these scores are close together when observing the rating scale. This pays tribute to the fact that the emergent strategy and deliberate strategy formulation processes are done in conjunction with one another (Maritz et al. 2011:110).

Hypothesis 3 tested to see if first year business management students saw the influence of leadership as important in order to have a successful organisational strategy. The results indicated that respondents agreed with this, with the mean score $(M=3.88)$ sitting on the upper side of the rating scale. This result is in accordance with previous studies as business leaders coordinate the formulation, implementation and other processes of organisational strategy, whether emergent or deliberate (Maritz et al. 2011:102-103). Without leadership in an organisational strategy, there is no success (Mayfield et al. 2015:98).

These findings indicate that respondents could identify the importance of leadership in organisational strategy as well as the effects that the different leadership styles can have on the formulation and implementation of an organisational strategy, whether it is an emergent strategy or a deliberate strategy, or a combination of both.

\section{Managerial implications}

It is clear to see that within an organisation the importance of an efficient and effective leadership style lies in achieving and maintaining high performance, with ever-changing conditions in the business environment (İşcan et al. 2014:882). The research conducted in this study indicates an outline of how leadership should be conducted in terms of the expectations of possible future business leaders (i.e. first year undergraduate business management students).

The leadership style that was most prominent to future business leaders in an organisation was transformational leadership. Although this is the preferred leadership style amongst future business leaders, a few characteristics of transactional leadership, which is seen as a good first step towards transformational leadership, can also be implemented, such as (1) rewards for tasks successfully completed and (2) acknowledgement of work progress (Thyer in Birasnav 2014:215). 'Leaders providing recognition and/or rewards when employees reach their goals' was the most important item that resulted from the transactional sub-dimension. Within the transformational sub-dimension, the most important item that resulted amongst first year undergraduate business management students indicated that managers should inform employees on how they are doing in terms of their work and overall performance.
In terms of the way future business leaders view organisational strategy, an emergent strategy is seen as more effective because it is flexible in nature and can be implemented with speed in complex business environments. Managers should include all organisational members in the implementation of the strategy as indicated in this study's results; this is in line with the transformational leadership style. Deliberate strategies should however not be excluded from the organisational strategies as they could still play a vital role in achieving an organisation's goals, and deliberate strategies should be developed in combination with emergent strategies (Maritz et al. 2011:110). Within the sub-dimension of deliberate strategy, first year undergraduate business management students still see the importance of creating and developing a strategy through a planned and formal process.

This study indicates that there is a definite importance in the influence that leadership has on an organisational strategy. Leadership should also be conducted in such a manner that future business people and future leaders will be able to work with and learn from, as well as to achieve success in organisations and have a successful organisational strategy.

\section{Limitations}

The first limitation of this study was that of the population sample. The fact that the sample was first year undergraduate business management students could in fact mean that their level of knowledge and experience in leadership and organisational strategy may have been limited. The result of a respondent misunderstanding a question is often unconscious misrepresentation (University of Pretoria 2016:2).

The second limitation pertaining to this study is that of the data collection instrument's inadequate internal reliability consistency for all six sub-dimensions. The Cronbach's alpha values indicated internal consistency values that fell short of the generally accepted value of 0.70 . These low values may have been attributed to a small number of items measuring each sub-dimension. Nonetheless, the scale items measuring these sub-dimensions lacked an internal reliability consistency. Nunnally (in Churchill 1976:68) however suggested that for early stages of basic research, if the reliability falls between 0.5 and 0.6 (i.e. the alpha score or value), then it is sufficient.

The third limitation with regard to this study comes from the use of a non-probability, quota sampling data collection method. A quota sample, even though the variables under study are representative, may not always truly reflect the intended target population entirely. The selection of respondents to take part in the survey was done by convenience, and not on a random basis. The true identity or representativeness of the sample for the target population is also questionable as it is unknown (University of Pretoria 2015b:10).

The fourth limitation of this study falls within the actual collection of the raw data. As respondents had to complete the survey within the first $10 \mathrm{~min}$ of their lecture, such time 
restraints could have formed a survey error called extremity bias. A few surveys received back, which were not included in the data analyses, displayed this extremity bias where respondents tend to only use the extreme points of the rating scale (University of Pretoria 2016:2).

\section{Recommendations for future research}

The first recommendation for future research focuses on the target population of the study. As the study focused solely on first year undergraduate students, the results of the study cannot necessarily be generalised to other contexts such as second year, third year and postgraduate students or even other universities in South Africa. Therefore, future studies should include a wider target population, not only on different academic levels but also between different tertiary institutions.

The second recommendation would be to increase the amount of time over which data is collected. As this study sought out to collect all of its data in one session at the beginning of a lecture, effects such as extremity bias could have taken place. Future researchers should try to eliminate this effect by expanding the time of data collection. In doing so, the researchers will have access to a larger pool of respondents, which will represent the targeted population better, and the respondents will have more time to properly answer all of the survey questions.

The third recommendation for future research is that this study could be conducted on the difference between future female leaders and future male leaders within organisations. As female leadership can be seen to demonstrate characteristics that highlight the importance of creating relationships and taking on an instructional leadership approach, male leadership concentrates on organisational matters and the completion of goals. Male leadership also points out reaching objectives and reward or punishment upon successful or unsuccessful completion of work (Growe \& Montgomery 1999). The difference between male and female preferred leadership styles could also provide important information for organisational managers in terms of facilitating leadership development or training future business leaders.

A final recommendation would be to include more leadership and organisational strategy theory in tertiary academic environments at an earlier academic level (i.e. first year undergraduate business management students). This could ensure that students grasp the importance of these two concepts and that theory pertaining to leadership and organisational strategy can be tested and understood before these students go into practice in a work-related business environment.

\section{Conclusion}

Rapid changes in the global business environment are forcing organisations to have a more flexible, dynamic and adaptive direction and strategy. As first year undergraduate business management students at the University of Pretoria form part of the next generation of possible business leaders, current organisations should seek ways to adapt their leadership approaches towards organisational strategy, and realise the importanceleadership has on having a successful organisational strategy. The transformational leadership style and emergent strategies are preferred amongst these students, and as these future business leaders are constantly developing and transforming within their current educational environment, tertiary institutions need to implement the correct leadership training and ensure that these students get exposed to not only the correct theories and literature but also to industry and practice. This will in turn create a stronger base of individuals who could become successful business leaders in the future, who will know how they should have to conduct themselves within a competitive business working environment to ensure organisational success.

This study could contribute to the success that leadership can have on the organisational strategy by understanding how leaders should act or behave. This study will also help understand the interdependence of these two constructs - in general, as well as from a South African perspective where very little research has been conducted on the topic under consideration.

If the correct and effective leadership training and development gets implemented on an early level (i.e. first year undergraduate studies), then these future leaders might also later be able to develop their followers and inspire or motivate them to develop as leaders themselves, which in turn could possibly create a basis of longevity of leadership and organisational success.

\section{Acknowledgements}

The author would like to acknowledge the reviewers of the draft manuscript, as well as Mr M.J. Forbes and Mr S.J. Pearce for their helpful assistance during the development, data collection and analyses of a draft version of this article.

\section{Competing interests}

The author declares that there are no financial or personal relationships that may have inappropriately influenced the writing of this article.

\section{Authors' contributions}

D.A.J.B. was the project leader and was also responsible for conceptualising the study and the study's methodology formulation.

\section{References}

Allio, R.J., 2016, 'Learning to be a leader', Strategy \& Leadership 44(4), 3-9. https:// doi.org/10.1108/SL-06-2016-0041

Birasnav, M., 2014, 'Relationship between transformational leadership behaviors and manufacturing strategy', International Journal of Organizational Analysis 22(2), 205-223. https://doi.org/10.1108/IJOA-10-2011-0520 
Bornman, D.A.J. \& Puth, G., 2017, 'Investigating employee perceptions of leadership communication: A South African study', Journal of Contemporary Management 14(1), 1-23.

Breevaart, K., Bakker, A., Hetland, J., Demerouti, E., Olsen, O.K. \& Espevik, R., 2014 'Daily transactional and transformational leadership and daily employee engagement', Journal of Occupational and Organizational Psychology 87(1) 138-157. https://doi.org/10.1111/joop.12041

Brews, P.J. \& Hunt, M.R., 1999, 'Learning to plan and planning to learn: Resolving the planning school/learning school debate', Strategic Management Journal 20(10), 889-913. https://doi.org/10.1002/(SICI)1097-0266(199910)20:10\%3C889:AIDSMJ60\%3E3.0.CO;2-F

Bryman, A. \& Bell, E., 2011, Business research methods, 3rd edn., Oxford University Press, Oxford.

Carmeli, A. \& Waldman, D.A., 2009, 'Leadership, behavioral context, and the performance of work groups in a knowledge-intensive setting', The Journal of Technology Transfer 35(4), 384-400. https://doi.org/10.1007/s10961-009-9125-3

Carpenter, M. \& Sanders, G., 2014, Strategic management concepts and cases, 2nd edn., Pearson Education Limited, Harlow.

Carter, C., Clegg, S.R. \& Kornberger, M., 2008, 'Strategy as practice?', Strategic Organization 6(1), 83-99. https://doi.org/10.1177/1476127007087154

Čater, T., Lang, R. \& Szabo, E., 2013, 'Values and leadership expectations of future managers: Theoretical basis and methodological approach of the GLOBE Student project', Journal for East European Management Studies 18(4), 442-462.

Churchill, G.A., 1976, 'A paradigm for developing better measures of marketing constructs', Journal of Marketing Research 16(1), 64-73. https://doi.org/ $10.2307 / 3150876$

Cooper, D.R. \& Schindler, P.S., 2014, Business research methods, 12th edn., McGraw Hill/Irwin, New York.

Denning, S., 2015, 'New lessons for leaders about continuous innovation', Strategy \& Leadership 43(1), 11-15. https://doi.org/10.1108/SL-11-2014-0083

Fenton, C. \& Langley, A., 2011, 'Strategy as practice and the narrative turn', Organization Studies 32(9), 1171-1196. https://doi.org/10.1177/0170840611410838

Giessner, S.R. \& Wong, S.I., 2017, 'The thin line between empowering and laissez-faire leadership: An expectancy-match perspective', Journal of Management 1(1) 1-52. https://doi.org/10.1177/0149206315574597

Growe, R. \& Montgomery, P., 1999, Women and the leadership paradigm: Bridging the gender gap, viewed 31 October 2016, from http://www.nationalforum.com

İşcan, Ö.F., Ersarı, G. \& Naktiyok, A., 2014, 'Effect of leadership style on perceived organizational performance and innovation: The role of transformational leadership beyond the impact of transactional leadership - An application amon Turkish SME's', Procedia - Social and Behavioral Sciences 150(1), 881-889. https://doi.org/10.1016/j.sbspro.2014.09.097

Kahane, A., 2017, 'Stretch collaboration: How to work with people you don't agree with or like or trust', Strategy \&Leadership 45(2), 42-45. https://doi.org/10.1108/ SL-02-2017-0013

Kopmann, J., Kock, A., Killen, C.P. \& Gemünden, H.G., 2017, 'The role of project portfolio management in fostering both deliberate and emergent strategy', International Journal of Project Management 35(4), 557-570. https://doi. org/10.1016/j.ijproman.2017.02.011
Kotzé, T., 2012, Honours research project: SPSS workshop 2, Department of Business Management, University of Pretoria, Pretoria.

Kunnanatt, J.T., 2016, '3D leadership - Strategy-linked leadership framework for managing teams', Economics, Management, and Financial Markets 11(3), $30-55$.

Küpers, W., Mantere, S. \& Statler, M., 2013, 'Strategy as storytelling: A phenomenological collaboration', Journal of Management Inquiry 22(1), 83-100. https://doi.org/10.1177/1056492612439089

Maritz, R., Pretorius, M. \& Plant, K., 2011, 'Exploring the interface between strategymaking and responsible leadership', Journal of Business Ethics 98(1), 101-113. $\mathrm{https}$ ://doi.org/10.1007/s10551-011-1024-5

Marx, T.G., 2015, 'The impact of business strategy on leadership', Journal of Strategy and Management 8(2), 110-126. https://doi.org/10.1108/JSMA-062014-0042

Mayfield, J., Mayfield, M. \& Sharbrough, W.C., 2015, 'Strategic vision and values in top leaders' communications: Motivating language at a higher level', International Journal of Business Communication 52(1), 97-121. https://doi.org/10.1177/ 2329488414560282

Porter, M.E., 1996, 'What is strategy?', Harvard Business Review 74(6), 61-78.

Pretorius, M. \& Maritz, R., 2011, 'Strategy making: The approach matters', Journal of Business Strategy 32(4), 25-31. https://doi.org/10.1108/02756661111150945

Raelin, J., 2011, 'From leadership-as-practice to leaderful practice', Leadership 7(2), 195-211. https://doi.org/10.1177/1742715010394808

Restivo, A.C., n.d., Multifactor Leadership Questionnaire (MLQ) Form 6S, viewed 03 June 2016, from http://alrestivo.com/Downloads.html

Sarros, J.C., Luca, E., Densten, I. \& Santora, J.C., 2014, 'Leaders and their use of motivating language', Leadership \& Organization Development Journal 35(3), 226-240. https://doi.org/10.1108/LODJ-06-2012-0073

Schoemaker, P.J.H. \& Krupp, S., 2015, 'Overcoming barriers to integrating strategy and leadership', Strategy \& Leadership 43(2), 23-32. https://doi.org/10.1108/SL-012015-0001

Tatum, B.C. \& Eberlin, R.J., 2007, 'Leadership, ethics, and justice in strategic decision making', Business Strategy Series 8(4), 303-310. https://doi.org/10.1108/ 17515630710684358

University of Pretoria, 2015a, Course notes for NME 704: Research methodology Notes on sampling and sample size determination, Department of Business Management, University of Pretoria, Pretoria.

University of Pretoria, 2015b, Course notes for NME 704: Research methodology Notes on sampling, Department of Business Management, University of Pretoria, Pretoria.

University of Pretoria, 2016, Course notes for NME 704: Research methodology Different forms of survey error, Department of Business Management, University of Pretoria, Pretoria.

Whittington, R., 2006, 'Completing the practice turn in strategy research', Organization Studies 27(5), 613-634. https://doi.org/10.1177/017084060 6064101

Yukl, G., 2006, Leadership in organizations, 6th edn., Pearson-Prentice Hall, Upper Saddle River, NJ. 